\title{
İşyerlerinde Güvenlik İklimi Kişisel Koruyucu Donanım Kullanımını Etkiler mi?
}

\author{
Hacer GÖK-UGUR ${ }^{1}$, Ayten YILMAZ-YAVUZ ${ }^{2}$, Nuran MUMCU $^{3}$ ve \\ Nurefşan AYDOĞAN ${ }^{4}$
}

Öz

Bu çalışma işyerlerindeki güvenlik ikliminin kişisel koruyucu donanım kullanımına etkisini belirlemek amacıyla yapılmıştır. Çalışma tanımlayıcı olarak Ocak-Mart 2016 tarihleri arasında Bir Ortak Sağlık ve Güvenlik Biriminin hizmet verdiği işyerlerinde çalışan işçiler üzerinde yapılmıştır. Araştırmanın evrenini işyerlerinde çalışan toplam 120 işçi, örneklemi ise araştırma kriterlerine uyan 104 işçi oluşturmuştur. Araştırmanın verileri "Bilgi Formu" ve "Güvenlik İklimi Ölçeği" kullanılarak yüz yüze görüşme tekniği ile toplanmıștır. Etik açıdan Ortak Sağlık ve Güvenlik Birimi’nden yazılı izin ve araştırmaya katılan işçilerden sözel onam alınmıştır. Verilerin değerlendirilmesinde tanımlayıcı istatistikler, bağımsız gruplarda t testi, varyans analizi, korelasyon testi ve lineer regresyon analizi kullanılmıştır. Araştırma kapsamındaki işçilerin \% 85,6's1 işyerinde kişisel koruyucu donanım kullanmanın önemli olduğunu düşündügünü ve \% 72,1'i işyerinde düzenli olarak kişisel koruyucu donanım kullandığını belirtmiştir. Araştırmada işçilerin güvenlik iklimi ölçeği puan ortalamaları ile kişisel koruyucu donanımı düzenli kullanmaları, kişisel koruyucu donanımın ulaşılabilir olması, kişisel koruyucu donanım kullanımı hakkında bilgi almaları, kișisel koruyucu donanım kullanımının kolay olmasıı ve kişisel koruyucu donanımı ekip arkadaşlarının düzenli kullanması arasında istatistiksel olarak anlamlı bir fark olduğu bulunmuştur ( $\mathrm{p}<0.05)$. Bu çalışmada ișçilerin algıladığı güvenlik ikliminin, kișisel koruyucu donanım kullanım durumlarını etkilediği belirlenmiștir. Bu sonuçlar doğrultusunda işverenlerin, güvenlik iklimi ve kişisel koruyucu ekipmanların kullanımı ile ilgili farkındalıklarının arttırılması önerilir.

Anabtar Kelimeler: İşyeri, Güvenlik İklimi, Kişisel Koruyucu Donanım, Çalışan

\section{Does Safety Climate at Workplaces Affect the Protective Safety Equipment Use?}

\section{Abstract}

This study was performed in order to determine the effect of safety climate on the personal protective equipment use at workplaces. This descriptive study was performed between January-March 2016 with employees working in workplaces which were audited by a Mutual Health and Safety Unit. The population of the study was composed of 120 individuals and the study group was composed of 104 workers who met the research criteria. The data of the study were collected by using 'Information Form' and 'Safety Climate Scale'. Before conducting the study, we obtained written approvals from Joint Health and Safety Units. The oral consents were obtained from employees who accepted to participate in the study. Descriptive statistics, independent sample t test, variance analyses, correlation test and linear regression analysis were used in order to evaluate the data of the study. Of all workers, $85,6 \%$ of them thought that the use of personal protective equipment was important, and $72,1 \%$ of them stated that they were regularly using personal protective equipment at workplace. There was a significant difference between the status of employees regarding the regular use availability, get sufficient information, ease of use, regular use of teammates of personal protective equipment, and safety scale scores $(p<0.05)$. In this study, the safety climate perceived by workers affected the status of using personal protective equipment In line with these findings, it is recommended to increase the awareness of employers related to the importance of the safety climate and the use of personal protective equipment in the workplace.

Key Words: Workplace, Safety Climate, Personal Protective Equipment, Employees

\section{Atıf İçin / Please Cite As:}

Gök-Uğur, H., Yılmaz-Yavuz, A., Mumcu, N. ve Aydoğan, N. (2020). İşyerlerinde güvenlik iklimi kişisel koruyucu donanım kullanımını etkiler mi? Manas Sosyal Arastırmalar Dergisi, 9(1), 168-177.

\footnotetext{
1 Öğr. Gör. Dr. - Ordu Üniversitesi Sağlık Bilimleri Fakültesi, hacer32@gmail.com - ORCID: 0000-0002-0371-0556

2 Dr. Öğr. Üyesi-Recep Tayyip Erdoğan Üniversitesi Sağlık, ayten.yilmaz@erdogan.edu.tr ORCID: 0000-0002-5861-4254

${ }^{3}$ Dr. Öğr. Üyesi-Ondokuz Mayıs Üniversitesi Sağlık Bilimleri Fakültesi, nuranm@omu.edu.tr ORCID: 0000-0002-9803-7172

${ }^{4}$ Uzman-Ordu Ortak Sağllk ve Güvenlik Birimi, nurefsan_aydogan@hotmail.com - ORCID: 0000-0002-8618-6074
} 


\section{Giriş}

Dünyada ve ülkemizde iş kazaları önemli bir halk sağlı̆̆ sorunu olup, Uluslararası Çalışma Örgütü verilerine göre; 2014 yllı içinde Dünya'da 3.133.535 kişinin iş kazası yaşadığı ve 9.197 kişinin iş kazası nedeniyle hayatını kaybettiği, Türkiye'de ise Sosyal Güvenlik Kurumu verilerine göre; 2015 yll içinde 241.547 kişinin iş kazası yaşadığı ve 1.252 kişinin iş kazası nedeniyle hayatını kaybettiği belirtilmektedir (Hämäläinen vd., 2006; SGK İstatistikleri, 2018). Bu veriler gelişmiş ve gelişmekte olan ülkelerde iş kazalarının ve buna bağlı ölümlerin önemli bir sorun olduğunu göstermektedir (Öçal ve Özal, 2017). İşyerlerinde iş kazalarının önlenerek güvenli bir çalışma ortamının oluşturulmasında güvenlik ikliminin anahtar bir kavram olduğu belirtilmektedir (Aytaç, 2011; Türen vd., 2014).

Güvenlik iklimi, işyerlerinde çalışanların çalısma ortamlarıyla ilgili algıladıkları temel algılardır. İşçilerin bu algılarını yöneticilerin güvenlik konusuna olan bağlılığı, işyerindeki güvenlikle ilgili politikalar, prosedürler, ödüllerin algılanış biçimi, çalışanların güvenlikle ilgili süreç ve işlemlere katılımı ve çalışanların işyerinde güvenliğe ne kadar değer verdiği etkilemektedir (Wiegmann vd., 2001; Neal ve Griffin, 2006). İsyerlerinde olumlu iş güvenliği ikliminin sağlanmasında örgüt yöneticilerinin konuya olan ilgisi ve çabaları büyük önem taşımaktadır. Bunun için yöneticilerin iş güvenliği konusuna gereken ilgiyi göstermeleri, iş güvenliği faaliyetlerine katılmaları, yürürlükte olan yasa, tüzük ve yönetmelikleri titizlikle uygulamaları, çalışanlarına iş güvenliği eğitim programlarını sağlamaları, örgüt içinde iş güvenliği hususlarını sürekli vurgulamaları, kaza sonrası yapılan araştırmaların suçlu aramak yerine problem çözme ve danışmanlık sağlama odaklı olması konusundaki destekleri çalışanların güvenli davranış sergilemeleri açısından önemlidir (Dejoy, 1985; Zohar, 1980; Demirbilek ve Çakır, 2008).

Literatür incelendiğinde çalışanların işyerlerinde algıladığı güvenlik ikliminin iş sağlığı ve güvenliği algılarını (Ören ve Er, 2016) ve güvenli davranışlarını etkilediği belirtilmektedir (Cooper ve Phillips, 2004; Sadullah ve Kanten, 2009; Tholen vd., 2013; Yorulmaz vd., 2016). Ayrıca çalışanların işyerlerinde algıladıkları güvenlik iklimi ile iş kazası yaşama durumları arasında ilişki olduğu çalsştıkları işyerini güvenli olarak algılayan çalışanların, tehlikeli olarak algılayan çalışanlara göre daha az iş kazası yaşadıkları belirlenmiştir (Hayes vd., 1998; Hofmann ve Stetzer, 1998; Griffin ve Neal, 2000; Clarke, 2006; Probst ve Estrada, 2010; Zhu vd., 2010; Smith ve DeJoy, 2012; Carol., 2014). Bununla birlikte iş kazalarının önlenmesinde örgüt yönetiminin önemli bir role sahip olduğu, iş kazaları henüz ortaya çıkmadan önce tehlikenin kaynağında kontrol altına alınmasının ve kişisel koruyucu donanım (KKD) kullanımının sağlanmasının önemli olduğu vurgulanmaktadır (Dursun, 2011). İş kazalarının çoğunlukla güvensiz davranışlardan kaynaklandığı ve iş yerlerinde uygun KKD kullanımının kaza meydana geldiğinde işçilerin vücut bütünlügünü korumalarına yardımcı olduğu belirtilmektedir (Wentz, 1998; Aybek vd., 2003). Bu noktada işyerinde işçilerin kişisel koruyucu donanım kullanmalanını etkileyen bireysel ve örgütsel değişkenler bulunmaktadır (Öçal ve Özal, 2017). İşçilerin KKD kullanımını etkileyen bireysel faktörlerle birlikte örgütsel faktörlerin belirlenmesi iş kazalarının önlenmesi açısından oldukça önemlidir. Bu çalışma işyerlerindeki güvenlik ikliminin kişisel koruyucu donanım kullanımına etkisini belirlemek amacıyla yapılmışır.

Araştırma Sorular1

1. İşçilerin kişisel koruyucu donanım kullanımı ile ilgili düşünceleri ve uygulamaları nasıldır?

2. Issçilerin sosyo-demografik özellikleri güvenlik iklimi algılarını etkiler mi?

3. Isşçilerin güvenlik iklimi algıları kişisel koruyucu donanım kullanımını etkiler mi?

\section{Yöntem}

Araştırma tanımlayıcı olarak Ocak-Mart 2016 tarihleri arasında bir Ortak Sağlık ve Güvenlik Biriminin hizmet verdiği işyerlerinde (Akaryakıt istasyonu, demir doğrama, gemi yapımı, matbaa, asansör bakım onarım gibi) çalışan işçiler üzerinde yapılmıştır. Etik açıdan araştırmaya başlamadan önce işyerlerinin bağlı olduğu Ortak Sağlık ve Güvenlik Birimi’nden yazılı izin ve araştırmaya katılan işçilerden sözel onam alınmıştır. Araştırmaya işyerlerinde kişisel koruyucu ekipman kullanımı zorunlu alanlarda çalısan ve araştırmaya katılmaya gönüllü olan işçiler dahil edilmiştir.

\section{Evren - Örneklem}

Araştırmanın evrenini işyerlerinde çalş̧an toplam 120 işçi, örneklemi ise araştırma kriterlerine uyan 104 işçi oluşturmuştur. 


\section{Veri Toplama Araçları}

Araştırmanın verileri "Bilgi Formu” ve "Güvenlik İklimi Ölçeği” kullanılarak yüz yüze görüşme tekniği ile toplanmıştır.

Bilgi Formu. Bu form araştırmacılar tarafindan literatür doğrultusunda (Öçal ve Özal, 2017; Ören ve Er, 2016; Wentz, 1998; Aybek vd., 2003) hazırlanmıştır. Form 3 bölümden oluşmaktadır. Birinci bölümde; işçilerin sosyo-demografik özellikleri (8 soru), ikinci bölümde; işçilerin iş sağlığı ve güvenliği ile ilgili özellikleri (11 soru) ve üçüncü bölümde; işçilerin kişisel koruyucu donanım kullanımı ile ilgili özelliklerini (8 soru) içeren toplam 27 soru yer almıştır.

Güvenlik İklimi Ölçeği. Ölçek, Choudhry vd. (Choudhry vd., 2009) tarafindan geliştirilmiş olup, Türkçe'ye Türen vd. (Türen vd., 2014) tarafından uyarlanmıştır. Hong Kong’ta inşaat firmalarında uygulanmış olan güvenlik iklimi ölçeği kısaltılarak orijinal ölçekte bulunan 22 madde içinden sekiz madde elenerek anlamsal olarak birbirinden ayrı 14 madde belirlenmiş ve kullanılmıştır. Likert tipte olan ölçek (1) Kesinlikle Katılmıorum, (2) Katılmıyorum, (3) Kararsızım, (4) Katılıyorum, (5) Kesinlikle Katıliyorum şeklinde puanlanmıştır. Ölçekte 1-5 aralığında bulunan bir değerin seçilmesiyle 1 en düşük 5 ise en yüksek durumu göstermektedir. Ölçeğin iki alt boyutu vardır. Birinci faktör: "Yönetimin Bakış Açısı ve Kurallar" olarak adlandırılmış olup ilk 10 soru bu faktörde yer almaktadır. İkinci faktör: "İş Arkadaşları ve Güvenlik Eğitimleri" olarak adlandırılmış olup 4 soru bu faktörde yer almaktadır. Ölçekte sorulan soruların tamamı aynı yöndedir. Sorulara verilen cevaplar sonucunda ne kadar çok puan elde edilirse işyeri güvenlik ikliminin çalışanlar tarafindan o derece pozitif algılandığı sonucu ortaya çıkmaktadır.

\section{Verilerin Analizi}

Araştırmanın verileri SPSS 20.0 paket programı kullanılarak değerlendirilmiştir. Verilerin normal dağılıma uygunluğu Kolmogorov Smirnov testi ile test edilmiş ve veriler normal dağıllım gösterdiği için parametrik testler kullanılmıştır. Verilerin değerlendirilmesinde tanımlayıcı istatistikler (sayı, yüzde, aritmetik ortalama, standart sapma), bağımsız gruplarda $t$ testi, varyans analizi, korelasyon testi ve lineer regresyon analizi kullanılmıştır. Araştırmada anlamlılık düzeyi 0,05 olarak alınmıştır.

\section{Bulgular}

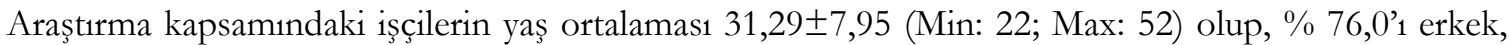

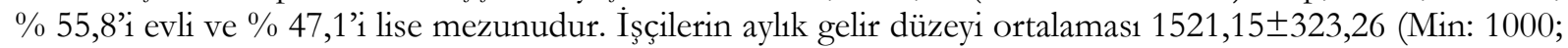

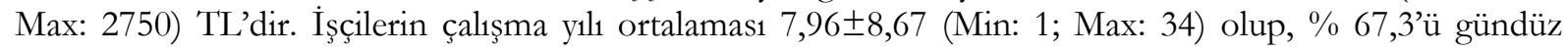
çalışmakta ve \% 30,8’i asansör bakım onarımında çalışmaktadır (Tablo 1).

Araştırma kapsamındaki işçilerin \% 7,7'sinin sağltk sorunu olduğu, \% 82,7'sinin işe girmeden önce sağlık muayenesi yaptırdığı, \% 37,5'inin düzenli aralıklarla sağlık muayenesi yaptırdığı ve \% 35,6'sının iş yerinde sağllk birimi olduğu belirlenmiştir. İşçilerin \%97,1'i iş sağlı̆̆ ve güvenliğinin önemli olduğunu düşündüğ̈̈nü, \% 70,2'si iş sağlığı ve güvenliği konusunda eğitim aldığını ve \% 33,7'si çalıştığı işle ilgili oryantasyon eğitimi aldığını belirtmiştir. İşçilerin \% 7,7’si meslek hastalığ tanısı aldığını, \% 22,1’i iş kazası yaşadığını, \% 43,5’i iş güvenliği olmayan çalışma ortamı nedeniyle iş kazası yaşadığını ve $\% 37,5^{\prime} \mathrm{i}$ iş yerinde

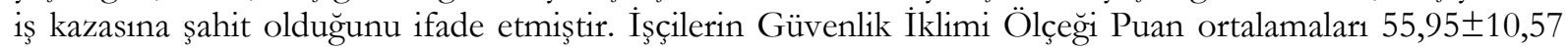
(Min:33; Max:70) olarak iyi düzeyde bulunmuştur (Tablo 2).

Araştırma kapsamındaki işçilerin \% 85,6's1 KKD kullanmanın önemli olduğunu, \% 72,1’i düzenli KKD kullandığını, \% 92,3'ü KKD'nin ișyerinde ücretsiz verildiğini, \% 83,7'si ișyerinde KKD'nin ulaşılabilir olduğunu, \% 73,1'i KKD kullanımı hakkında bilgi aldığını, \% 63,5’i KKD kullanımının kolay olduğunu, \% 85,6'sı işverenin KKD kullanımına önem verdiğini ve \% 53,8'i işyerinde ekip arkadaşlarının düzenli olarak KKD kullandığını belirtmiştir (Tablo 3). 
Tablo 1. Isş̧ilerin Sosyo-Demografik Öz̨elliklerinin Dağgllmm

\begin{tabular}{|c|c|c|c|}
\hline Tanıtıcı Özellikler & & $N$ & $\%$ \\
\hline Yaş ortalaması & & 31,29 $\pm 7,95$ (Min:22;Max:52) & \\
\hline \multirow{2}{*}{ Cinsiyet } & Kadın & 25 & 24,0 \\
\hline & Erkek & 79 & 76,0 \\
\hline \multirow{2}{*}{ Medeni durum } & Evli & 58 & 55,8 \\
\hline & Bekâr & 46 & 44,2 \\
\hline \multirow{4}{*}{ Eğitim durumu } & İlkokul & 20 & 19,2 \\
\hline & Ortaokul & 17 & 16,3 \\
\hline & Lise & 49 & 47,1 \\
\hline & Üniversite & 18 & 17,3 \\
\hline Aylık gelir ortalaması & & 1521,15_323,26 (Min:1000; Max:2750) & \\
\hline Çalışma yılı ortalaması & & 7,96 $\pm 8,67$ (Min:1; Max:34) & \\
\hline \multirow{2}{*}{ Çalışma sistemi } & Gündüz & 70 & 67,3 \\
\hline & Vardiyalı & 34 & 32,7 \\
\hline \multirow{6}{*}{ Çalışma alanları } & Akaryakit istasyonu & 22 & 21,2 \\
\hline & Demir doğrama & 6 & 5,7 \\
\hline & Gemi yapımı & 14 & 13,5 \\
\hline & Matbaa & 6 & 5,7 \\
\hline & Asansör bakımı & 32 & 30,8 \\
\hline & Diğer & 24 & 23,1 \\
\hline Toplam & & 104 & 100,0 \\
\hline
\end{tabular}

Tablo 2. Issçilerin İs Sağhl̆ğ ve Güvenliğ̀i ile İlgili Özelliklerinin Dağglhm

\begin{tabular}{|c|c|c|c|}
\hline \multicolumn{2}{|c|}{ İs Sağlı̆̆1 ve Güvenliği İle İlgili Özellikler } & \multirow{2}{*}{$\begin{array}{c}N \\
\end{array}$} & \multirow{2}{*}{$\frac{\%}{7,7}$} \\
\hline & Evet & & \\
\hline Sagglik sorunu olma durumu & Hayır & 96 & 92,3 \\
\hline \multirow{2}{*}{$\begin{array}{l}\text { İşe girmeden önce sağllk muayenesi } \\
\text { yaptırma }\end{array}$} & Evet & 86 & 82,7 \\
\hline & Hayır & 18 & 17,3 \\
\hline \multirow{2}{*}{$\begin{array}{l}\text { Düzenli aralıklarla sağlık muayenesi } \\
\text { yaptırma }\end{array}$} & Evet & 39 & 37,5 \\
\hline & Hayır & 65 & 62,5 \\
\hline \multirow{2}{*}{ İş yerinde sağlık birimi olma durumu } & Evet & 37 & 35,6 \\
\hline & Hayır & 67 & 64,4 \\
\hline \multirow{4}{*}{$\begin{array}{l}\text { İş sağllğ̆ ve iş güvenliğinin önemli } \\
\text { olduğunu düşünme } \\
\text { İş sağllğ̣ ve iş güvenliği konusunda } \\
\text { eğitim alma }\end{array}$} & Evet & 101 & 97,1 \\
\hline & Hayır & 3 & 2,9 \\
\hline & Evet & 73 & 70,2 \\
\hline & Hayır & 31 & 29,8 \\
\hline \multirow{2}{*}{$\begin{array}{l}\text { Çalıştı̆̆ı işle ilgili oryantasyon eğitimi } \\
\text { alma }\end{array}$} & Evet & 35 & 33,7 \\
\hline & Hayır & 69 & 66,3 \\
\hline \multirow{2}{*}{ Meslek hastalığı tanısı alma } & Evet & 8 & 7,7 \\
\hline & Hayır & 96 & 92,3 \\
\hline \multirow{2}{*}{ İş kazası yaşama } & Evet & 23 & 22,1 \\
\hline & Hayır & 81 & 77,9 \\
\hline \multirow{3}{*}{ İş kazası yaşama nedeni $(n=23)$} & Güvenli olmayan çevre & 9 & 39,1 \\
\hline & İş güvenliği olmayan çalışma ortamı & 10 & 43,5 \\
\hline & Diğer & 4 & 17,4 \\
\hline \multirow{2}{*}{ İşyerinde iş kazasına şahit olma } & Evet & 39 & 37,5 \\
\hline & Hayır & 65 & 62,5 \\
\hline Güvenlik İklimi Ölçeği Puanı & $55,95 \pm 10,57(\Lambda$ & & \\
\hline
\end{tabular}


Tablo 3. Isş̧ilerin Kişisel Koruyucu Donanım Kullanımı İle İlgili Özelliklerinin Dă̆ğlmı

\begin{tabular}{|c|c|c|c|}
\hline \multirow{3}{*}{$\begin{array}{l}\text { KKD ile ilgili özellikler } \\
\text { KKD kullanmanın önemli olduğunu } \\
\text { düşünme }\end{array}$} & & $N$ & $\%$ \\
\hline & Evet & 89 & 85,6 \\
\hline & Hayır & 15 & 14,4 \\
\hline \multirow{2}{*}{ KKD’yi düzenli kullanma } & Evet & 75 & 72,1 \\
\hline & Hayır & 29 & 27,9 \\
\hline \multirow{2}{*}{$\begin{array}{l}\text { KKD'nin işveren tarafindan ücretsiz } \\
\text { verilmesi }\end{array}$} & Evet & 96 & 92,3 \\
\hline & Hayır & 8 & 7,7 \\
\hline \multirow{2}{*}{ KKD'nin işyerinde ulaşılabilir olması } & Evet & 87 & 83,7 \\
\hline & Hayır & 17 & 16,3 \\
\hline \multirow{2}{*}{ KKD kullanımı hakkında bilgi alma } & Evet & 76 & 73,1 \\
\hline & Hayır & 28 & 26,9 \\
\hline \multirow{2}{*}{ KKD kullanımının kolay olması } & Evet & 66 & 63,5 \\
\hline & Hayır & 38 & 36,5 \\
\hline \multirow{2}{*}{$\begin{array}{l}\text { İşverenin KKD kullanımına önem } \\
\text { vermesi }\end{array}$} & Evet & 89 & 85,6 \\
\hline & Hayır & 15 & 14,4 \\
\hline Ekip arkadaşlarının düzenli KKD & Evet & 56 & 53,8 \\
\hline kullanmasi & Hayır & 48 & 46,2 \\
\hline \multicolumn{2}{|l|}{ Toplam } & 104 & 100,0 \\
\hline
\end{tabular}

\section{KKD=Kişisel Koruyucu Donanım}

Araştırmada işçilerin tanıtıcı özellikleri ile güvenlik iklimi ölçeği puan ortalamaları arasında istatistiksel olarak anlamlı bir fark olmadığı bulunmuştur $(p>0,05)$. İşçilerin çalıştı̆̆ alan ile güvenlik iklimi ölçeği puan ortalamaları arasında istatistiksel olarak anlamlı bir fark olduğu belirlenmiştir $(p<0,05)$. Demir doğrama alanında çalışan işçilerin güvenlik iklimi algıları diğer alanlarda çalışanlara göre daha yüksektir (Tablo 4).

Tablo 4. Isş̧ilerin Tanıtıc Özullikleri ile Güvenlik İklimi Ölçeği Puan Ortalamalarmın Karşılaştırılması

\begin{tabular}{|c|c|c|c|}
\hline Tanıtıcı Özellikler & \multicolumn{2}{|c|}{$X \pm S S$} & Test ve $p$ değeri \\
\hline Yaş ortalaması & \multicolumn{2}{|c|}{$31,29 \pm 7,95$} & $\mathrm{r}=0,540$ \\
\hline \multirow{2}{*}{ Cinsiyet } & Kadın & $57,68 \pm 8,99$ & $t=0,938$ \\
\hline & Erkek & $55,41 \pm 11,02$ & $p=0,351$ \\
\hline \multirow{2}{*}{ Medeni durum } & Evli & $55,78 \pm 10,58$ & $\mathrm{t}=-0,190$ \\
\hline & Bekâr & $56,17 \pm 10,66$ & $p=0,850$ \\
\hline \multirow{4}{*}{ Eğitim durumu } & İlkokul & $53,00 \pm 10,97$ & $\mathrm{~F}=1,120$ \\
\hline & Ortaokul & $53,94 \pm 12,48$ & $p=0,345$ \\
\hline & Lise & $57,43 \pm 10,09$ & \\
\hline & Üniversite & $57,11 \pm 9,27$ & \\
\hline Aylık gelir ortalamas1 & \multicolumn{2}{|c|}{$1521,15 \pm 323,26$} & $\begin{array}{l}\mathrm{r}=-0,110 \\
p=0,266\end{array}$ \\
\hline Çalışma yılı ortalaması & \multicolumn{2}{|c|}{$7,96 \pm 8,67$} & $\begin{array}{l}\mathrm{r}=-0,087 \\
p=0,381\end{array}$ \\
\hline \multirow{2}{*}{ Çalışma sistemi } & Gündüz & $57,09 \pm 10,86$ & $\mathrm{t}=1,581$ \\
\hline & Vardiyalı & $53,62 \pm 9,68$ & $p=0,117$ \\
\hline \multirow{6}{*}{ Çalışma alanları } & Akaryakıt istasyonu & $58,64 \pm 7,02$ & $\mathrm{~F}=3,513$ \\
\hline & Demir doğrama & $62,50 \pm 13,92$ & $p=0,006$ \\
\hline & Gemi yapımı & $61,93 \pm 10,35$ & \\
\hline & Matbaa & $52,17 \pm 5,95$ & \\
\hline & $\begin{array}{l}\text { Asansör bakım } \\
\text { onarım }\end{array}$ & $51,13 \pm 11,06$ & \\
\hline & Diğer & $55,75 \pm 10,19$ & \\
\hline
\end{tabular}

Araştırma kapsamındaki işçilerin Güvenlik İklimi Ölçeği puan ortalamaları ile KKD'yi düzenli kullanma, KKD'nin işyerinde ulaşılabilir olması, KKD kullanımı hakkında bilgi alma, KKD kullanımının kolay olması ve ekip arkadaşlarının düzenli KKD kullanımı arasında istatistiksel olarak anlamlı bir fark olduğu bulunmuştur $(\mathrm{p}<0,05)$. İşyerinde KKD'yi düzenli kullanan, KKD'ye iş yerinde kolay ulaşabilen, KKD kullanımı konusunda bilgi alan, kullandığı KKD'si rahat olan ve ekip arkadaşları düzenli KKD kullanan işçilerin güvenlik iklimi algıları daha yüksektir. Araştırma kapsamındaki işçilerin Güvenlik İklimi Ölçeği puan ortalamaları ile KKD kullanmanın önemli olduğunu düşünme, KKD’nin işveren tarafindan 
ücretsiz verilmesi ve işverenin KKD kullanımına önem vermesi arasında istatistiksel olarak anlamlı bir fark olmadığ1 belirlenmiştir ( $\mathrm{p}>0,05)$ (Tablo 5).

Tablo 5. Isş̧ilerin Güvenlik İklimi Ölçeği Puan Ortalamalar ile Kişisel Koruyucu Donanım Kullanma Durumlarmın Karşılaștıriması

\begin{tabular}{|c|c|c|}
\hline KKD İle İlgili Özellikler & & Güvenlik İklimi Ölçeği $X \pm S S$ \\
\hline \multirow{3}{*}{ KKD kullanmanın önemli olduğunu düşünme } & Evet & $56,42 \pm 10,70$ \\
\hline & Hayır & $53,20 \pm 9,62$ \\
\hline & $\mathrm{t} / \mathrm{p}$ & $\mathrm{t}=1,091 / p=0,278$ \\
\hline \multirow{3}{*}{ KKD’yi düzenli kullanma } & Evet & $57,53 \pm 9,85$ \\
\hline & Hayır & $51,86 \pm 11,42$ \\
\hline & $\mathrm{t} / p$ & $\mathrm{t}=2,517 / p=0,013$ \\
\hline \multirow{3}{*}{ KKD'nin işveren tarafından ücretsiz verilmesi } & Evet & $56,04 \pm 10,47$ \\
\hline & Hayır & $54,88 \pm 12,37$ \\
\hline & $\mathrm{t} / p$ & $\mathrm{t}=0,299 / p=0,766$ \\
\hline \multirow{3}{*}{ KKD'nin işyerinde ulaşılabilir olması } & Evet & $57,33 \pm 9,73$ \\
\hline & Hayır & $48,88 \pm 12,11$ \\
\hline & $\mathrm{t} / p$ & $\mathrm{t}=3,143 / p=0,002$ \\
\hline \multirow{3}{*}{ KKD kullanımı hakkında bilgi alma } & Evet & $57,68 \pm 9,70$ \\
\hline & Hayır & $51,25 \pm 11,54$ \\
\hline & $\mathrm{t} / p$ & $\mathrm{t}=2,848 / p=0,005$ \\
\hline \multirow{3}{*}{ KKD kullanımının kolay olması } & Evet & $58,76 \pm 9,27$ \\
\hline & Hayır & $51,08 \pm 11,02$ \\
\hline & $\mathrm{t} / p$ & $\mathrm{t}=3,793 / p=0,000$ \\
\hline \multirow{3}{*}{ İşverenin KKD kullanımına önem vermesi } & Evet & $56,56 \pm 10,63$ \\
\hline & Hayır & $52,33 \pm 9,72$ \\
\hline & $\mathrm{t} / p$ & $\mathrm{t}=1,441 / p=0,153$ \\
\hline \multirow{3}{*}{ Ekip arkadaşlarının düzenli KKD kullanması } & Evet & $60,27 \pm 8,75$ \\
\hline & Hayır & $50,92 \pm 10,35$ \\
\hline & $\mathrm{t} / \mathrm{p}$ & $\mathrm{t}=4,994 / p=0,000$ \\
\hline
\end{tabular}

KKD=Kişisel Koruyucu Donanım

Tablo 6. İş̧ilerin Güvenlik İklimi Ölçeği Puanlarnmn Yordanmasına İlişkin Regreasyon Analizi

\begin{tabular}{|c|c|c|c|c|c|c|c|}
\hline Değisken & $B$ & $\begin{array}{c}\text { Standart } \\
\text { Hata }\end{array}$ & Beta & $t$ & $p$ & Tolerance & $V I F$ \\
\hline Sabit & 69,368 & 5,052 & & 13,732 & 0,000 & & \\
\hline $\begin{array}{l}\text { KKD kullanmanın önemli olduğunu } \\
\text { düşünme }\end{array}$ & $-1,373$ & 3,002 & 0,046 & 0,457 & 0,649 & 0,761 & 1,315 \\
\hline KKD’yi düzenli kullanma & 2,607 & 2,885 & 0,111 & 0,904 & 0,369 & 0,505 & 1,979 \\
\hline KKD'nin ücretsiz verilmesi & 8,791 & 4,476 & 0,223 & 1,964 & 0,052 & 0,595 & 1,681 \\
\hline KKD'nin ulaşılabilir olması & $-8,521$ & 3,571 & 0,300 & 2,386 & 0,019 & 0,485 & 2,062 \\
\hline KKD hakkinda bilgi alma & 0,881 & 3,135 & 0,037 & 0,281 & 0,779 & 0,438 & 2,285 \\
\hline KKD kullanımının kolay olması & $-3,899$ & 2,480 & 0,179 & 1,572 & 0,119 & 0,593 & 1,686 \\
\hline $\begin{array}{l}\text { İşverenin KKD kullanımına önem } \\
\text { vermesi }\end{array}$ & 0,758 & 3,228 & 0,025 & 0,235 & 0,815 & 0,658 & 1,520 \\
\hline $\begin{array}{l}\text { Ekip arkadaşlarının düzenli KKD } \\
\text { kullanması }\end{array}$ & $-7,797$ & 2,501 & 0,370 & 3,117 & 0,002 & 0,544 & 1,838 \\
\hline $\mathrm{R}=0,523$ & $\mathrm{R}^{2}=0,273$ & & & & & & \\
\hline $\mathrm{F}_{(8,95)}=4,469 \quad \mathrm{p}=0,000$ & & & & & & & \\
\hline
\end{tabular}

\section{KKD $=$ Kişisel Koruyucu Donanım}

Araştırmada KKD kullanmanın önemli olduğunu düşünme, KKD’yi düzenli kullanma, KKD’nin işveren tarafından ücretsiz verilmesi, KKD'nin işyerinde ulaşılabilir olması, KKD kullanımı hakkında bilgi alma, KKD kullanımının kolay olması, işverenin KKD kullanımına önem vermesi, ekip arkadaşlarının düzenli KKD kullanması değişkenleri işçilerin Güvenlik İklimi Ölçeği ile anlamlı bir ilişki vermektedir $(\mathrm{R}=0,523, \mathrm{R} 2=0,273, \mathrm{p}<0,05)$. KKD kullanmanın önemli olduğunu düşünme, KKD’yi düzenli kullanma, KKD'nin işveren tarafindan ücretsiz verilmesi, KKD'nin işyerinde ulaşılabilir olması, KKD kullanımı hakkında bilgi alma, KKD kullanımının kolay olması, işverenin KKD kullanımına önem vermesi, ekip 
arkadaşlarının düzenli KKD kullanması değişkenleri işçilerin Güvenlik İklimi Ölçeğinin toplam varyansının \%27'sini açıklamaktadır. Regresyon katsayılarının anlamlllı̆ına ilişkin t testi sonuçları incelendiğinde KKD'nin işyerinde ulaşılabilir olması ve ekip arkadaşlarının düzenli KKD kullanması değişkenlerinin Güvenlik İklimi Ölçeği üzerinde anlamlı bir yordayıcı olduğu görülmektedir (Tablo 6).

\section{Tartışma, Sonuç ve Öneriler}

$\mathrm{Bu}$ bölümde, işyerlerindeki güvenlik ikliminin kişisel koruyucu donanım kullanımına etkisini belirlemek amacıyla yapılan çalışmanın bulguları literatür doğrultusunda tartışılmıştır. Araştırmada işçilerin güvenlik iklimi ölçeği puan ortalamaları ile KKD'yi düzenli kullanma, KKD’nin işyerinde ulaşılabilir olması, KKD kullanımı hakkında bilgi alma, KKD kullanımının kolay olması ve ekip arkadaşlarının düzenli KKD kullanması arasında istatistiksel olarak anlamlı bir fark olduğu bulunmuştur. Regresyon analizinde KKD'nin işyerinde ulaşılabilir olması ve ekip arkadaşlarının düzenli KKD kullanması değişkenlerinin Güvenlik İklimi Ölçeği üzerinde anlamlı bir yordayıcı olduğu görülmüştür. Alkış ve Taşpınar (2012) Konya'da metal sanayi iş kolunda faaliyet gösteren işletmelerde istihdam edilen 120 iş görenin katılımı ile yapmış oldukları çalışmada, çalş̧anların güvenlik iklimi algıları ile iş sağlığı ve güvenliği arasında pozitif yönlü bir ilişki olduğu bulunmuştur. Sadullah ve Kanten (2009) Çanakkale'de tersane çalışanları üzerinde yaptıkları çalışmada güvenlik iklimi ile güvenlik davranışları arasında ilişki olduğunu belirlemişlerdir. Tholen vd. (2013) İsveç'de tünel işçileri üzerinde yaptıkları çalışmada güvenlik ikliminin bireysel algısının, bireysel güvenlik davranışını etkilediğini bulmuşlardır. Yorulmaz vd. (2016) tarafından tersane işletmelerinde yapılan çalışmada, çalışanların güvenlik yönetimi uygulamaları ve çalışma ortamlarına yönelik algılarının güvenliğe ilişkin davranışlarını etkilediği belirlenmiştir. Bununla birlikte Cooper ve Philips (2004) paketleme fabrikasında çalışanların algıladıkları güvenlik ikliminin iş kazası yaşama durumlarını ve güvenli davranışlarını etkilediğini belirlemişlerdir. Probst ve Estrada (2010) farklı sektörlerde çalışanlar üzerinde yaptıkları çalışmada, güvenlik ikliminin pozitif algılandığı durumlarda çalışanların daha az kazaya maruz kaldığını tespit etmişlerdir. Zhu vd. (2010) tarafından Çin'de yapılan çalışmada güvenlik ikliminin olumlu algılandığ1 örgütlerde, çalışanların daha az iş kazasına uğradıkları belirlenmiştir. Smith ve Dejoy (2012) ABD'de yaptıkları çalışmada, güvenlik ikliminin iş kazalarını önlediğini tespit etmişlerdir. Carol vd. (2014) Hong-Kong'da tamir, bakım ve onarım sektöründe çalışanlar üzerinde yaptıkları çalışmada pozitif güvenlik algısı ile güvenlik kuralları ve düzenlemelerine uymanın çalş̧anların iş kazası geçirme olasıllğını azalttı̆̆ belirlenmiştir. Diğer taraftan Wentz (1998) uygun KKD kullanımına yönelik işçi tutumunun büyük ölçüde işletme yönetiminin tutumundan etkilendiğini ve KKD kullanımını algılanan yönetim desteğinin, kolaylık, konfor ve kullanım rahatlığının, kullanmaya ilişkin ihtiyacı anlamanın, kullanmama durumunda ortaya çıkan ekonomik kayıpların ve diğer işçilerin algıladığı kabulün etkilediğini belirtmektedir. Dünya'da önde gelen araştırma ve danışmanlık kuruluşlarından biri olan Frost ve Sullivan (2018) tarafindan 1001 kişinin katılımıla İngiltere, Fransa, İtalya, İskandinavya, Polonya ve ABD gibi pek çok ülkede yürütülen "Kişisel Koruyuculara Karşı Kullanıcıların Yaklaşımı" konulu araştırmada çalışanlar için en önemli faktörün, kullandıkları ürünün konforu ve kullanım kolaylığı olduğu belirtilmektedir. Ayrıca Demirbilek ve Çakır (2008) KKD kullanımını ilk sırada ulaşılabilirliğin, ardından güvenlik ihtiyacı ve son olarak iş kazasına uğramış olma durumunun etkilediğini belirtmektedir. Taşçı (2016) ise, işyerlerinde KKD kullanımında devlet, işveren, iş sağlığı ve güvenliği profesyonelleri ve çalışanların ayrı ayr1 sorumluluklarının olduğunu, özellikle işverenin yaklaşımının çalışanlar üzerinde ciddi manada etkisinin olduğunu, eğitim, yaptırım ve denetimin tam anlamıyla gerçekleştirilecek olmasının olumlu yönde davranış değişikliğine etkisinin olacağını gözlemlemiştir. Bu çalışmada KKD'yi işçilerin düzenli kullanmaları, KKD’nin işyerinde ulaşılabilir olması, işçilerin KKD konusunda bilgi almış olmaları, KKD kullanımının kolay olmasının ve işçilerin ekip arkadaşlarının KKD kullanmalarının güvenlik ikliminden etkilenme durumları literatürle uyumludur. Çalışma kapsamında işçilerin güvenlik iklimini pozitif algılamalarına bağlı olarak KKD ile ilgili bu özelliklerin etkilendiği söylenebilir.

Araştırmada işçilerin güvenlik iklimi ölçeği puan ortalamaları ile KKD kullanmanın önemli olduğunu düşünme, KKD'nin işveren tarafindan ücretsiz verilmesi ve işverenin KKD kullanımına önem vermesi arasında istatistiksel olarak anlamlı bir fark olmadığı belirlenmiştir. Güvenlik iklimi, çalışanların çalışma güvenliğine ilişkin psikolojik algisı olarak belirtilmektedir (Yorulmaz vd., 2016; Guldenmund, 2000). Bununla birlikte Taşçı (2016) çalışanların KKD kullanmama nedenlerini; işçilerin psikolojik durumları, aşırı kendine güven duygusu ve bana bir şey olmaz mantığı olduğunu ifade etmektedir. Demirbilek ve Çakır (2008) ise, çalışanların güvenli davranış sergilemesinde güvenlik ihtiyacı hissetmeleri gerektiği ve bu güvenlik ihtiyacınında çalışma ortamında sağlğ̆ ve güvenliği tehdit eden tehlikelerin algılanmasıyla ilişkili olduğunu belirtmektedir. Bu çalışmada işçilerin KKD kullanımının önemli olduğunu düşünme, KKD'nin 
işveren tarafından ücretsiz verilmesi ve işverenin KKD kullanımına önem vermesi durumlarının güvenlik ikliminden etkilenmemesinin işçilerin psikolojik algılarıyla ilgili olduğu düşünülmektedir. Bununla birlikte araştırmanın sadece bir ildeki ortak sağılı ve güvenlik birimine kayıtlı işçiler üzerinde yapılmış olması sonuçların genellenebilirliği açısından bir sınırlılık arz etmektedir.

Araştırmada işçilerin çoğunun KKD kullanmanın önemli olduğunu düşündüğü, düzenli KKD kullandığı, KKD kullanımı hakkında eğitim aldığı, KKD kullanımının kolay olduğunu düşündüğü ve işverenin KKD kullanımına önem verdiğini düşündüğü bulunmuştur. İşçilerin KKD'yi düzenli kullanma, KKD'nin işyerinde ulaşılabilir olması, KKD kullanımı hakkında bilgi almaları, KKD kullanımının kolay olması ve ekip arkadaşlarının düzenli KKD kullanması durumlarının güvenlik ikliminden etkilendiği, ancak KKD kullanmanın önemli olduğunu düşünme, KKD'nin işveren tarafindan ücretsiz verilmesi ve işverenin KKD kullanımına önem vermesi durumlarının güvenlik ikliminden etkilenmediği bulunmuştur. $\mathrm{Bu}$ sonuçlar doğrultusunda; sağlık profesyonelleri tarafindan güvenlik ikliminin KKD kullanımına etkisi konusunda işverenlerin farkındalıklarının artırılması ve işyerlerinde işçilerin konuyla ilgili bireysel algılarının değerlendirilerek eğitimlerin yapılması KKD’nin düzenli kullanımını sağlayarak iş kazalarının önlenmesinde etkili olacaktır.

\section{Kaynakça}

Alkış, H. ve Taşpınar, Y. (2012). İşçi sağlığı ve iş güvenliğinde yeni yaklaşımlar, demir çelik sektörü çalısanlarının işçi sağlığı ve iş güvenliği algısi: Konya örneği. IISS 12. Uluslararası Demir Celik Semposyumu, Karabük.

Aybek, A., Güvercin, Ö. ve Hurşitoğlu, Ç. (2003). Teknik personelin iş kazalarının nedenleri ve önlenmesine yönelik görüşlerinin belirlenmesi üzerine bir araştırma. KSÜ Fen ve Mühendislike Dergisi, 6(2), 91-100.

Aytaç, S. (2011). İ̧̧ kazalarını önlemede güvenlik kültürünün önemi. Türk Metal Dergisi, 147, 1-8.

KH Hon, C., Hinze, J. ve PC Chan, A. (2014). Safety climate and injury occurrence of repair, maintenance, minor alteration and addition works: A comparison of workers, supervisors and managers. Facilities, 32(5/6), 188-207.

Choudhry, R. M., Fang, D.ve Lingard, H. (2009). Measuring safety climate of a construction company. Journal of Construction Engineering and Management, 135(9), 890-899.

Clarke, S. (2006). The relationship between safety climate and safety performance: a meta-analytic review. Journal ofOccupational Health Psychology, 11(4), 315-327.

Cooper, M. D. ve Phillips, R. A. (2004). Exploratory analysis of the safety climate and safety behavior relationship. Journal of Safety Research, 35(5), 497-512.

Dejoy, D. M. (1985). Attributional processes and hazard control management in industry. Journal of Safety Research, 16(2), 61-71.

Demirbilek, T. ve Çakır, Ö. (2008). Kişisel koruyucu donanim kullanimini etkileyen bireysel ve örgütsel değişkenler. Dokuz Eylïl Üniversitesi İktisadi İdari Bilimler Fakültesi Dergisi, 23(2), 173-191.

Dursun, S. (2011). Güvenlik kïltürünün güvenlik performansı üzerine etkisine yönelik bir uygulama (Doktora Tezi). Uludăg Üniversitesi, Sosyal Bilimler Enstitüsü, Bursa.

Frost \& Sullivan understanding perceptions and attitudes towards personal protection equipment: Us\&Europeanusers. 19 Haziran 2018 tarihinde http://www.frost.com/sublib/subscriptionndex.do? pageSize $=100 \&$ subscriptionId $=9310 \&$ bdata $=\&$ page $=1$ adresinden erişildi.

Griffin, M. A. ve Neal, A. (2000). Perceptions of safety at work: a framework for linking safety climate to safety performance, knowledge, and motivation. Journal of Occupational Health Psycbology, 5(3), 347-358.

Guldenmund, F. W. (2000). The nature of safety culture: a review of theory and research. Safety Science, 34(1-3), 215257.

Hämäläinen, P., Takala, J. ve Saarela, K. L. (2006). Global estimates of occupational accidents. Safety Science, 44(2), $137-156$.

Hayes, B. E., Perander, J., Smecko, T. ve Trask, J. (1998). Measuring perceptions of workplace safety: Development and validation of the work safety scale. Journal of Safety Research, 29(3), 145-161.

Hofmann, D. A. ve Stetzer, A. (1998). The role of safety climate and communication in accident interpretation: Implications for learning from negative events. Academy of Management Journal, 41(6), 644-657.

Neal, A. ve Griffin, M. A. (2006). A study of the lagged relationships among safety climate, safety motivation, safety behavior, and accidents at the individual and group levels. Journal of Applied Psychology, 91(4), 946-953.

Öçal, M. ve Çiçek, Ö. (2017). Türkiye ve Avrupa Birliği’nde iş kazası verilerinin karşılaştırmalı analizi. Hak $\dot{I}_{s}$ Uluslararasi Emek ve Toplum Dergisi, 6(16), 616-637.

Ören, K. ve Er, M. (2016) Güvenlik ikliminin güvenlik performansına etkisi. Hak Ișs Uluslararası Emek ve Toplum Dergisi, 5(13), 48-66.

Probst, T. M. ve Estrada, A. X. (2010). Accident under-reporting among employees: Testing the moderating influence of psychological safety climate and supervisor enforcement of safety practices. Accident Analysis \& Prevention, 42(5), 1438-1444.

Sadullah, Ö. ve Kanten, S. (2009). A research on the effect of organizational safety climate upon the safe behaviors. Ege Akademik Bakus Dergisi, 9(3), 923-932. 
SGK İstatistikleri. 19 Haziran 2018 tarihinde https://artidanhaberler.files.wordpress.com/2017/02/isg-kaza-vemeslek-hastalc4b1c49fc4b1-istatistigi_07-02-2017.pdf adresinden erişildi.

Smith, T. D. ve DeJoy, D. M. (2012). Occupational injury in America: An analysis of risk factors using data from the General Social Survey (GSS). Journal of Safety Research, 43(1), 67-74.

Taşç1, H. (2016). Kişisel koruyucu donanmlan çalışanlarn isteği ile kullanmama nedenleri ve kullandirma çözümleri (Yüksek Lisans Tezi). Gedik Üniversitesi Sosyal Bilimler Enstitüsü, İstanbul.

Tholén, S. L., Pousette, A. ve Törner, M. (2013). Causal relations between psychosocial conditions, safety climate and safety behaviour-A multi-level investigation. Safety Science, 55, 62-69.

Türen, U., Gökmen, Y., Tokmak, İ. ve Bekmezci, M. (2014). Güvenlik iklimi ölçeğinin geçerlilik ve güvenilirlik çalışması. Süleyman Demirel Üniversitesi İktisadi ve İdari Bilimler Fakültesi Dergisi, 19(4), 171-190.

Wentz, C. A. (1998). Safety, health, and environmental protection. McGraw-Hill Companies, Boston.

Wiegmann, D. A., Zhang, H. ve Von Thaden, T. L. (2001). Defining and assessing safety culture in high reliability systems: An annotated bibliography. University of Illinois at Urbana-Champaign, Aviation Research Lab.

Yorulmaz, M., Büyük, N. ve Birgün, S. (2016). Tersane işletmelerinde örgütsel güvenlik ikliminin incelenmesi. International Journal of Social Science, 46, 303-317.

Zhu, C. J., Fan, D., Fu, G. ve Clissold, G. (2010). Occupational safety in China: Safety climate and its influence on safety-related behavior. China Information, 24(1), 27-59.

Zohar, D. (1980). Safety climate in industrial organizations: theoretical and applied implications. Journal of Applied Psychology, 65(1), 96-102.

\section{EXTENDED ABSTRACT}

Safety climate is the basic perceptions of the employees about their working environment in the workplace. These perceptions of the employees are influenced by managers' commitment to safety, safetyrelated policies in the workplace, procedures, perception of rewards, employee involvement in safetyrelated processes and procedures, and how much employees value safety in the workplace. In addition, it is emphasized that organizational management has an important place in preventing work accidents and that it is important to take the danger under control at its source, to design working systems in an ergonomic way to minimize the risks and to provide the use of personal protective equipment (PPE) before work accidents occur. It is stated that work accidents mostly occur due to unsafe behaviors and appropriate PPE use in workplaces help in workers' protecting their physical integrity when an accident occurs. At this point, there are individual and organizational variables affecting the use of personal protective equipment by workers in the workplace. Identifying individual factors and organizational factors affecting PPE use of workers is important for the prevention of work accidents. This study was conducted to determine the effect of safety climate in the workplace on the use of personal protective equipment.

This descriptive study was conducted in January-February-March 2016 on workers working in the workplaces served by a Joint Health and Safety Unit. The population of the study consisted of 120 workers working in the workplaces, and the sample consisted of 104 workers who met the research criteria. The data of the research was collected by using "Information Form" and "Safety Climate Scale" using face-to-face interview technique. Ethically, written permission was taken from the Joint Health and Safety Unit and verbal consent was obtained from the workers who participated in the study. Descriptive statistics, independent samples $t$ test, variance analysis, correlation test and linear regression analysis were used to evaluate the data.

The mean age of the workers in the study was $31.29 \pm 7.95$ (Min: 22; Max: 52); 76.0\% were male, $55.8 \%$ were married and $47.1 \%$ were high school graduates. The average working year of the workers was 7,96 \pm 8,67 (Min: 1; Max: 34); 67.3\% worked daytime and 30.8\% worked in elevator maintenance and repair. It was found that $7.7 \%$ of the workers had a health problem, $82.7 \%$ had a health check before starting to work, $37.5 \%$ had a health check periodically and $35.6 \%$ had a health unit at work. $97.1 \%$ of the workers thought that occupational health and safety is important, $70.2 \%$ stated that they received occupational health and safety training and $33.7 \%$ stated that they received orientation training about their job. $7.7 \%$ of the workers stated that they were diagnosed with occupational disease, $22.1 \%$ had a work accident, $43.5 \%$ had a work accident due to a non-occupational safety environment and $37.5 \%$ witnessed a work accident at work. The mean score of the workers' Safety Climate Scale was found to be $55.95 \pm$ 10.57 (Min: 33; Max: 70). 85,6\% of the workers in the study stated that PPE use was important, 72,1\% stated that they used PPE regularly, 92,3\% stated that PPE was given free at workplace, $83,7 \%$ stated that PPE was accessible at workplace, $73,1 \%$ stated that they were informed about PPE use, $63,5 \%$ stated that PPE use was easy, 85,6 \% stated that their employers placed importance on PPE use and 53,8\% stated that their friends used PPE regularly. In the study, it was found that there was no statistically significant 
difference between the descriptive characteristics of the workers and the mean scores of the safety climate scale $(p>0,05)$. Statistically significant difference was found between the workers' field and the mean scores of the safety climate scale $(p<0,05)$. Workers working in the field of iron joinery had higher safety climate perception. In the study, statistically significant difference was found between workers' mean safety climate scale scores and using PPE regularly, PPE being accessible in the workplace, being informed about PPE, use of PPE being easy and regular PPE use of team mates $(p<0,05)$. Workers who use PPE regularly in the workplace, those who can access PPE easily at the workplace, those who are informed about PPE use, those whose PPE is easy to use and those whose friends use PPE regularly have higher safety climate perceptions. No statistically significant difference was found between the workers' safety climate scale mean scores and thinking that PPE use is important, PPE being given free by the employer and the employers' placing importance on PPE use ( $p>0,05)$. In the regression analysis, thinking that PPE use is important, using PPE regularly, PPE being given free by the employer, PPE being accessible in the workplace, being informed about PPE use, easy PPE use, employers' placing importance on PPE use and regular PPE use by teammates were found to explain $27 \%$ of the total variance of Safety Climate Scale. When the $t$ test results of the significance of regression coefficients are examined, it can be seen that PPE being accessible in the workplace and regular PPE use by teammates were significant predictors on Safety Climate Scale. In the study, it was found that most of the workers thought PPE use was important, they used PPE regularly, they were trained about PPE use, they thought PPE use was easy and they thought that the employer placed importance on PPE use. It was found that workers' regular PPE use, PPE being accessible in the workplace, being informed about PPE use, PPE use being easy and team mates' regular PPE use were influenced by safety climate, while their states of thinking that PPE use is important, PPE being given free by the employer and the employer placing importance on PPE use were not influenced by safety climate. In parallel with these results, health professionals' increasing the awareness of employees about the influence of safety climate on PPE use and training the individual perceptions of workers about the issue in workplaces will be effective in preventing work accidents through regular use of PPE. 